\title{
But (and MaIS) as Morpheme(s)
}

(But (e Mais) como Morfema(s))

\author{
François Nemo \\ (Université d'Orléans. ATRID \\ Département Sciences du langage)
}

ABstract: A morphemic-indicational description of English but (and French mais) is proposed, showing that the uses of but whose closer equivalents (and French translation) are almost, except, only, and without, together with the considerable variety of its connective uses, may be accounted for within a single semantic description. It is shown that but and mais do not encode metacommunicational indications about the relationship between the connected utterances, as is commonly believed and asserted, but provide a rather aspectual information/indication, whose interpretation is contextual and constructional. It is hence shown that but and mais's description should be split into levels: the description of the indication encoded by the morpheme, which is active in all its uses, and the description of the constructional interpretation the indication receives when the morpheme is inserted in a given construction - such as But for X, Y or P but $Q$ - or used in a specific context. The efficiency of this description is shown to support the Indicational-Indexical Semantics - IIS - framework approach. An introduction to this framework and to its relationship with the instructional semantics mainstream on the one hand, and with the procedural/conceptual distinction on the other hand, is also proposed.

KEY-WORDs: Discourse Connectives; Polysemy; Instructional Semantics.

RESUMO: Propõe-se uma descrição indicacional e morfêmica dos itens lexicais but (inglês) e mais (francês), que mostra que os diferentes usos de but (mas) podem ser explicados por uma única descrição semântica, abrangendo os usos equivalentes a almost (quase), except (exceto), only (somente) e without (sem), além da considerável variedade de usos conectivos. Mostra-se que but e mais, ao contrário do que normalmente é sustentado na literatura, não codificam indicações metacomunicacionais sobre as relaçöes entre sentenças conectadas, mas fornecem uma informação/indicaşão de caráter aspectual, cuja interpretação é construcional e contextual. Mostra-se então que a descri- 
ção de but e mais deve ser separada em niveis: a descrição da informaçãa codificada pelo morfema, que permanece ativa em todos os seus usos, e a descrição da interpretação construcional que a indicação semântica recebe quando o morfema é inserido numa dada construção - tais como But for X, Y ou P but Q-, ou é usado num contexto específico. A eficiência desta descrição serve de fundamento para a abordagem da Semântica indexical e indicacional. Propõe-se também uma introdução a essa teoria, em sua relação com o modelo de semântica instrucional dominante e com a dicotomia procedural/conceptual.

Palavras-Chave: Conectivos Discursivos; Polissemia; Semântica Instrucional.

\section{Introduction}

Various approaches have been developed throughout the history of discourse words studies, among which the following can be mentioned:

- Discourse-words based approaches to discourse theory (Ducrot, 1969, 1973,1976, 1977, 1980a, 1985; Ducrot \& Anscombre 1980, 1983) or utterance value (Nemo, 1992, 1996, 1999a);

- Relevance-based approaches of DWs (Blakemore, 1987; Luscher 1994, Rouchota)

- Discourse-based approaches of DWs (Schiffrin, 1987; DRT)

- Speech-act based approaches of DWs (Fraser, 1987, 1996, 1998)

- Distribution-based approaches of DWs (Rossari, 1993; Jayez \& Rossari, 1996)

The main differences among those approaches is:

1) the way they consider discourse words function:

- In Ducrot's first models DWs' function is to indicate the functions of the utterances connected. DWs are described in instructional terms;

- RT models, built explicitly (Wilson \& Sperber, 1990, 1993) on a procedural renaming of Ducrot's instructions, see DWs as a guide for utterance interpretation (Lusher, 1994); 
- Speech-act based approaches consider that DWs have a connective function, and that their meaning is what is done when using a DW. Hence, DWs belong to functional classes, such as CDM (contrastive discourse markers), elaborative discourse markers, etc.;

- Distributionally-focused approaches share the idea that DWs are part of functional families defined by what is done when using a DW, but use this pragmatic characterization as a mere background, the semantics of each DW being related to its syntactic distribution

2) the way they consider morphemic continuity and polyfunctionality:

- in the first kind of approaches, all the uses of a morpheme are to be considered (Ducrot, 1972), whether they are functionally equivalent or not (Nemo, 1998a);

- in the second kind of approach, no relation is made between the various uses of the same morpheme and the diversity of uses does not have to be accounted for. Reformulating enfin, for instance, or deductive donc are hence treated separately from their other uses and only in contrast to "other reformulating or deductive markers" (Rossari, 1993). Similarly, a non-defined notion of contrastiveness is given as central to the description of but, disregarding (see Fraser, 1998, note 3) many, if not most, of its uses. Such approaches actually favour functional family approaches (contrasting all the discourse words that can do the same kind of thing: to reformulate or to signal contrast, for instance) rather than morphemic approaches (accounting for all the uses of one morpheme and for its polyfunctionality)

In recent works (Nemo, 1998a, 2000, 2001) I have attempted to show that the procedural (RT) renaming of Ducrot's instructions is misleading, because instructions are actually indications/index and not procedures. I have also pointed out that the general idea according to which the meaning of DWs should be metacommunicational (and hence functional) should be reversed: semantic meaning must account for metacommunicational uses and not the other way round; metacommunicative function is not the core semantic meaning of such morphemes.

In this paper I wish to illustrate and test these two claims in the case of but and mais, clearly the two most documented DWs so far, by describing the indications they provide and showing through their most different uses how the same indications are used in each context. 
This description will allow me to discuss the full words/tool words distinction, showing that there is no difference between the morphemes mais and but and morphemes like table or balayer (to sweep): indications are declarative utterances (of the form: There is $\mathrm{X}$ and $\mathrm{Y}$ ) with no reference but with indexical backing (Look around and you will find what $\mathrm{X}$ and $\mathrm{Y}$ are in this context), the only difference between those morphemes and the so called full words (mots pleins) being the memorization of the contextual interpretation of the indications in the last case.

I will hence show that it is possible to account for all the uses of but in English, for instance, and not only for the connective uses, by describing the indication encoded by the morpheme but, i.e. the indication which is present and active in all the constructions in which but occurs and in every context.

Such an approach, I would like to argue, does not only account for all the uses of a morpheme, such as mais and but, but for the functional interpretation of each use. Thus instead of trying to describe the 'core' meaning of discourse words in functional terms, the main problem is showing not what is done when using a DW but how it is done.

\section{The IIS Framework ...}

The IIS framework belongs to the Instructional Semantics Framework which has been developed since the early seventies, following Oswald Ducrot's formulation of the notion of instruction (1981) in order to account for the semantics of "connecteurs argumentatifs", such as mais (but) or puisque (since), and "opérateurs argumentatifs", such as même (even), presque (almost) or à peine (nearly, hardly). It focuses on making the difference between the notion of instructional meaning and the notion of procedural meaningclear, following Wilson \& Sperber's $(1990,26)$ claim that procedural analysis would be able to explain Ducrot's descriptive success "Comment les conclusions des analyses complexes que Ducrot a consacré à mais et d'autres particules comparables peuvent-elles être à la fois si simples et si révélatrices? L'analyse procédurale suggère une réponse à ces questions" ("How can the conclusions of Ducrot's complex analysis about mais and other similar particles be at the same time so simple and so revealing? Procedural analysis provides an answer to these questions."). In a few words (for a detailed 
discussion of this issue, see Nemo, 2000 and Nemo, 2001), IIS highlights the non-procedural - and actually declarative - nature of instructions ${ }^{1}$, showing that it is not possible to say that words (and discourse words) encode procedural meaning, since all the instructions must be decomposed into two parts: i) an indication (i.e. an information of the 'There is $\mathrm{X}$ and $\mathrm{Y}^{\prime}$ type); and ii) the indexical instruction (Look in the context for what may unify with $\mathrm{X}$ and $\mathrm{Y}$ ). This last indexical instruction is not morphemespecific, and hence cannot be said to be encoded, whereas the indications are both morpheme-specific and encoded.

In contradiction thus with the thesis that there are two types of linguistic (encoded) meaning (conceptual meaning and procedural meaning) and that a word encoded meaning is either conceptual or procedural, the Indicational-Indexical Semantics thesis is that there is only one type of linguistic (encoded) meaning (i.e. indications) though two types of information may be attached to a sign; i) coded information (indications); and ii) memorized interpretations of the indications.

The IIS thesis hence may be spelled out as follows:

1) the semantic (encoded) meaning of a morpheme provides the same indication(s) in all uses and contexts;

2) the possibility to use a morpheme only depends on the possibility to relate these indications to contextual elements. This process is called contextual unification;

3) the morpheme's linguistic meaning does not specify or limit the kind of elements that may be contextually unified with the indications it provides;

4) interpretation, hence, may be described as a process of unification of semantic indications and contextual elements.

It is these claims, and especially the claim that all morphemes encode only declarative information (indications), i.e. information which is neither referential nor procedural (nor functional), that we shall test here focusing

\footnotetext{
${ }^{1}$ A similar identification of the two notions may be found in Moeschler et al., (1998,8) "La notion de procédure est très proche de celle d'instruction beritée de la pragmatique intégrée" ('The notion of procedure is very close to the notion of instruction inherited from the Pragmatique Intégrée framework).
} 
on but and mais, two discourse words that since the early seventies have received every possible semantic and pragmatic description, and which are often believed to be prototypical examples of encoded functional, metacommunicational or procedural meaning.

\section{2. ..., non-intuitive semantics ...}

But another aspect of instructional semantics should be highlighted before proceeding to the actual morphemic description of but and mais. Instructional semantics (and hence IIS) is a consequence of a deeper claim about the role of intuition in semantics. From the very start, Instructional Semantics has argued for a non-intuitive approach to the question of linguistic meaning. According to non-intuitive semantics, semanticists should consider the actual distribution of semantic units to decide for their signification (linguistic meaning) rather than focus on semantic intuition as the starting point of a semantic analysis. In such a view, significations are to semantics what rules were to syntax (i.e. they have to produce the correct output), a position which is as opposed as possible to the traditional intuitive approach according to which we should consider certain uses as central or prototypical, revealing the 'core' semantic meaning, and we should considered other uses as peripherical, or extension, of results of the fading of the core meaning, etc. A typical illustration of this way of working can be given by considering the recent semantic description of but by Bruce Fraser (1998), who simultaneously claims that:

- the core meaning of but is to signal simple contrast, nothing else, and the speaker will select it when intending to bighlight a contrast.

- I can offer no precise definition of what qualifies as a Contrastive Discourse Marker (CDM).

- I call for your intuition that each of the [listed] CDMs signals a contrastive relationship between the [segment] S2 they introduce and a foregoing $S 1$.

- But is by far the most ubiquitous and general of the CDMs.

- I am not treating other uses of but such as found in: "All but one left today", "There was no doubt but that he won", "it has not sooner started but it stopped", "He was but a poor man", "I may be wrong but I think you are beautiful”. Whether or not they could be included under my analysis is left open. 
- Even if one cannot find two specific areas of contrast between the direct S2 and S1 messages, the messages may nevertheless be contrasted in one of several ways.

Such analysis, it must be observed, cannot be tested with any precision and is therefore unfalsifiable, either because of the non-formulation of the notion of contrastiveness or because of its shift between cases for which a certain notion of contrast is obvious and intuitive (Peter is tall but John is small), cases where it is not ${ }^{2}$ (Peter is tall but so is Peter) but where we are told that we should find anyway a 'deep' contrast, and cases for which the so-called 'semantic' contrast has actually no pragmatic counterpart: Fraser goes as far as saying that in an utterance such as "John gave toys to Mary but Sara gave dolls to Jane", there would be three areas of contrast, even though from a pragmatic point of view, such an utterance could perfectly (and probably would most of the time) be used to say, for instance, something like "John and Sara cannot be contrasted (and are both nice kids, so that we shouldn't treat John better than Sara) since they both gave toys to friends of theirs". In other words, what Fraser's example is showing is that but may perfectly be used "when the speaker intends to highlight the absence of contrast", exactly as in Peter is tall but so is Peter.

Within non-intuitive semantics, all of these claims would be said to rely on pure intuition, and it would be stated that linguistics should not be a theory of intuition but a theory of the actual behaviour of linguistic units. Moreover, it would be claimed that no semanticists or pragmaticists are needed if that is to repeat what has been written in dictionaries for hundreds of years: it may be the case that lexicography is enough and semantics is not needed, but then we should drop pretending doing semantics.

\section{3. ... and the morpheme/lexeme distinction.}

An illustration of the kind of difference brought by the distinction between intuitive and non-intuitive approaches to semantics in everyday

\footnotetext{
${ }^{2}$ It must be noticed that this last example is somehow more natural than the first one in the sense that it is easier to imagine a situation in which it would be uttered. Not that Fraser's examples are not natural in some contexts, they are easy to imagine too, but it would be wrong to think that but in such an example could mean something as "John is tall; Peter on the contrary is small".
} 
work is the example of the semantic unit table. If we call in first our semantic intuition, then it is quite clear that the 'core' semantic meaning of table is the conceptual/referential designation of a certain kind of piece of furniture. However, if we consider [table] in terms of semantic distribution, it is quite clear that considering uses, such as une table à manger (dining table), une table à langer (changing table), une table de multiplication (arithmetic charts), une table des matières (book contents), une table de montage (editing bench), un tableau (board, chart, table), un tableau de bord (instrument panel, dashboard), une tablette (shelf, bar), un tableur (spreadsheet) or les Tables de la loi (The Tables of the law), tabler sur (to count on something), dresser un tableau de la situation (to paint a picture of the situation), se mettre à table (to tell everything), and in English, a timetable, leads us to distinguish between the morpheme table, which can be described semantically (Nemo, 1999a) and which is present in all these uses, and the lexeme table. According to this morpheme/lexeme distinction, we should not mix, as is routinely done in intuitive semantics (following dictionaries), the meaning of the morpheme $[$ table $]$ and the meaning of the syntagm a table. This is because a table is a semantically complex unit since it combines the meaning of $a$ and table in a construction which has its specific semantics, and because $a$ table is not table, as becomes apparent when the morpheme is used as a verb. Similarly, according to this distinction, we should distinguish between the morpheme ever, and the lexeme ever, since the former is present in other words such as every, whenever, whoever, (and even possibly never) etc. with a constant meaning, and the latter receives a specific interpretation because of its specific syntactic status.

As we shall see, one of the advantages of the IIS and of the nonintuitive approach is that they allow for a homogenous semantic description of different word classes: if instructional semantics started with the description of discourse words at the end of the seventies, its use has later been extended to the semantic description of prepositions, nouns, adverbs, affixes and recently verbs (Gasiglia, Nemo \& Cadiot, 2001). More importantly, it has allowed a unified account of the semantics of morphemes such as French toujours (always, still, nevertheless) and encore (still, again, if even, however, etc.), i.e. of morphemes whose distribution overlaps the conceptual/procedural distinction. It was indeed possible to show that even though toujours, for instance, may be used in adverbial or 
connective positions, it encodes the same semantic indications in the two cases, which are interpreted either in an adverbial or a connective context (Nemo, 1998a, 1999a, 2001), so that there is a unique morpheme toujours and different lexemes toujours.

This means that morphemes are purely semantic units, whereas lexemes are semantic-syntactic units ${ }^{3}$, so that it can be said (Fischer \& Nemo, 2000; Nemo, 2001) that:

i) morphemes become lexemes only by entering particular constructions;

ii) as lexemes then, they may belong to a particular word class, which is specified by the respective construction;

iii) constructions narrow the possibilities of interpretation of the indications provided by the morpheme;

iv) constructional interpretations may be memorized and become part of the semantic content associated with a lexeme. These memorized interpretations of the lexemes, however, should not be mistaken with linguistic encoded meaning, for they are only lexical memorized interpretations.

As we shall see now, this distinction will prove to be directly useful when it comes to the actual description of the morpheme but.

\section{Describing but}

The advantage of English but over French mais is that it occurs in various constructions, so that it becomes very easy to illustrate simultaneously the morpheme/lexeme/construction distinction and the role of contextual unification in the interpretation of the indications provided by a morpheme. But, indeed, may occur in various syntactic positions, among which:

\footnotetext{
${ }^{3}$ For instance, English able and -able (and ability actually) may be said to be the same morpheme, if and because they share the same meaning. They become different lexemes as soon as a different combinatory (i.e., grammatical) piece of information and different semantic interpretations are attached to them.
} 
1) Broward had all but finished counting on Tuesday night, and the other two counties both said they could finish in time for the Monday deadline.

2) These results are all but absolute. In twenty years, only four observations of the opposite are recorded.

3) On Monday, key Kostunica aide Zoran Djindjic indicated Yugoslavia's new management was out to rebuild ties to the West which were all but destroyed under Milosevic.

4) Low cost and high speed are but two of the advantages of electronic data handling.

5) Until then, Democrats in the Capitol corridors and chambers - even outside Washington - will all but read from Gore's song sheet.

6) With the Texas governor and his deep-pockets GOP allies stretching Gore thin, the Democratic vice president has reduced by more than two thirds his ad campaign in the battleground state of Obio - all but conceding those 21 electoral votes.

7) This phenomenal rate cannot but have some effect on the children.

8) She couldn't eat anything but cucumbers.

9) All but one of the thieves were caught.

10) But for Peter, I would be dead.

11) Some of the government supporters will say things might have been worse but for the free trade agreement.

12) When Alcan takes all but 14 per cent of the water of the Nechako, we need to know not just what the effect of taking that water out will be in running down the Kemano River.

13) She had planned to make the certification of a winner on Saturday, but after the court ruling, said she would follow the court's decision.

14) Vedrine - like President Clinton and dozens of other Western leaders - were sentenced in absentia to 20 years in jail by Milosevic's court last month for ordering the NATO airstrikes. But Kostunica and other pro-democracy leaders here no longer consider Milosevic's decisions valid.

15) Secretary of State Madeleine Albright has spoken of "accountability" and respect for "the rule of law" but not of a Milosevic extradition.

16) The Israeli army had announced Monday that the three soldiers were wounded in the ambush but were probably alive.

17) Defense Secretary William Cohen said he knew of no other specific threats against American forces in the region, but said he ordered an increased alert level for all U.S. forces around the world, including those in the United States.

18) Albright said she would discuss with Barak and Arafat creating a mechanism to allow the sides to implement agreements on a cease-fire and return to peace talks, but gave no details. 
19) Arafat and Ivanov met in the Gaza Strip, and Arafat said afterward the two "discussed in detail everything to save the peace process, and how to protect it in spite of all the challenges we are facing." But he renewed accusations that Israel has used excessive force against rioters.

20) It's nearly three o'clock but the heat seems not to want to go down.

In these examples, we can first separate examples (1) to (12), in which but is not in a connective position, and is not a discourse marker, from examples (13) to (20) in which but does connect two utterances. We can further separate the non-connective examples depending both on the kind of construction or context in which but occurs and the semantic interpretation it takes:

i) the but for construction and without interpretation of examples (10) and (11);

ii) the 'all/everyone but' context and except interpretation of examples (9)and (12);

i) the 'all but' context and almost interpretation of examples (1) to (3)

ii) the 'all but' context and no other option interpretation of examples (5) and even (6);

iii) the only interpretation of examples (4), (7) and (8);

Given the fact that mais or aber, for instance, cannot be used in the French or German equivalent of examples (1) to (12), it would be easy to conclude that what we have here are different semantic and lexical units, and that in English, there is no semantic continuity between the use of but in examples (1) to (12) and the use of but in examples (13) to (20), or within examples (1) to (12). As stated earlier, I will actually show the opposite, namely that examples (1) to (20) are indeed a variety of uses of the same morpheme but and that the without, except, almost, only, no other option interpretations of these various but are local (and possibly memorized) interpretation through a process of contextual unification of the same indication provided (and encoded) by the morpheme.

\subsection{The meaning of but}

Whenever but is used, it indicates that: 


\section{(has been)}

\section{(could have been)}

\section{(should be) $)_{4}$}

In other words, the presence of but indicates the existence of a stopping factor, which may be successful or not, and which may be (most of the time) descriptive/constative or (sometimes) prescriptive/performative/ sui-referential. Because this indication has its own presupposition, namely that something was going on that is (has been, could have been, should have been) stopped, a simpler way to describe the indication is graphical.

Whenever but is used then, the hearer has to find in the context of use the two following steps:

t0
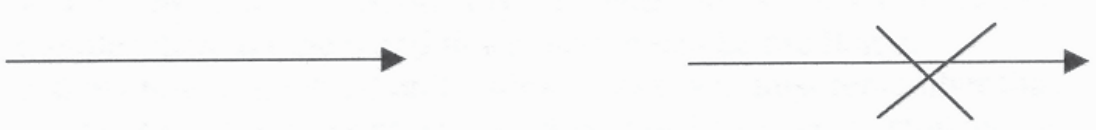

As in any unification process, contextual unification does not mean that any use of but must look like this; thus to utterances such as I tried to phone but the line was busy, what it says is only that any use of but must include this pattern, so that unification may be a success. Hence, when the stopping factor is not successful, very frequently we may have something like:

\footnotetext{
${ }^{4}$ The fact that the indication may receive both constative and performative (directive) readings, and various temporal unification, is not specific of but; it is the source of the considerable polyfunctionality of enfin for instance (see Nemo, 1999). The same could be said of what something refers to/unifies with. In some uses of mais, which could be named Gricean mais, such as:

- Devine ce que je mange

- Guess what I am eating

- Des bonbons

- Candies

- Gagné! Mais à quoi?

- Right!! But which flavour?

it is the issue of not telling which flavours, and hence the maxim of quantity, which is at stake in the use of but, whose interpretation thus is close to: "your answer is correct but not complete, don't stop, you must precise the flavour".
} 


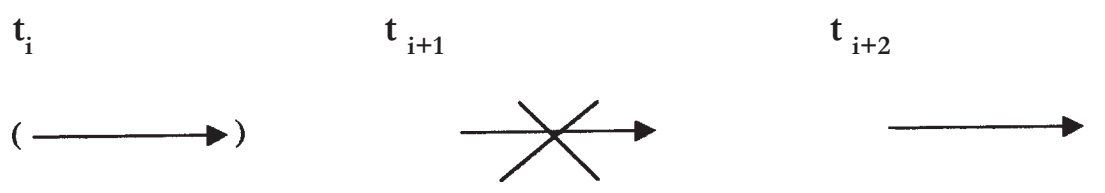

in which something is initiated, encounters difficulties, but is finally completed.

Before explaining how this indication can generate in each case the interpretations that may be observed in examples (1) to (20) and many others, it must be noticed that if this description is correct, the information but encodes is more aspectual than metacommunicational, as it deals with the fact that something is, or is not, completed. As we shall see, even if the formulation which has been chosen tries to avoid being too specific in terms of what it may apply to, it does impose some aspectual limits to the scenario encoded by but. Consequently, it will apply better to some examples than to others and this situation can be predicted.

To show how contextual unification works, we must remember that according to this description, but does not say what is stopped or what is the stopping factor but just urges to look for it/one. As a result, describing the uses of but means describing how in a context, the content of the indication is related to contextual elements. As we shall see, contextual unification is both a creative process (sometimes) and a highly routine process (most of the time, based on memorized interpretative patterns). As for this last case, and whenever a stable relationship is established between the content of the indication and a specific contextual element, we shall from now on speak of the existence of a semantic construction, i.e. of the existence of a fixed pattern of interpretation of the indication. We must thus distinguish between the notions of semantic construction and syntactic construction: various semantic constructions may be associated with the same syntactic context. For instance, nobody would distinguish two syntactic constructions in "The weather is nice but I am tired" and "I am tired but the weather is nice", but as far as unification with the indication encoded by but is concerned, they must be distinguished since the stopping factor is before but in the second case and after but in the first one, which of course is very important for the interpretation of the utterances. 
But let us describe now some of the most frequent semantic constructions associated with but, before considering later on more open unification processes. In order to do so, we shall start with the connective constructions before considering the other uses of but. Most of the data used was collected from the Internet (Excite news)

\subsubsection{The SFAB construction}

The SFAB construction is a construction in which $p$ occurs in a connective position and in which the Stopping Factor or Stop occurs after But. Quite frequently, it is associated with a successful stop, but unification only requires the existence of a stopping factor. Typical examples of SFAB constructions are examples (13) to (14) and the following:

21) This flat is beautiful but expensive ${ }^{5}$.

22) Bush has a 930-vote lead after machine counts of the 6 million ballots cast in the state in the presidential election two weeks ago, and the Republican secretary of state in Florida - Katherine Harris - had wanted to certify him as victor on Nov. 18. But the Supreme Court blocked that plan pending its consideration of the case this week.

23) The secretary of state may ignore such late filed returns," ruled Leon County Circuit Court Judge Terry Lewis, "but may not do so arbitrarily, rather, only by the proper exercise of discretion after consideration of all appropriate facts and circumstances."

24) "We all want finality, but not at the expense of fairness," Daschle, D-S.D., said on the Senate floor after detailing the months-long recount that awarded him his House seat in 1979.

25) This is very kind of you but I will be out of town on Saturday.

\footnotetext{
${ }^{5}$ This kind of examples was central to Ducrot's falsification of the logical descriptions (i.e. in terms of denial of expectations) of but, for it is clear that it cannot be said that the fact that a flat is beautiful would lead anybody to expect that it would be cheap. Ducrot's description in terms of argumentative orientation and instruction, however, due to its insistence on the fact that $\mathrm{p}$ and $\mathrm{q}$ are leading to opposite conclusions, was both very efficient and in a sense too efficient, for it was not making any distinction between SFAB and SFBB constructions, which finally made the identification of mais' encoded meaning more difficult.
} 
26) Well, she is nearly always in by ten. But (she could be late as) she has a lot of work at the library. (Fraser, 1998)

27) The WFL is a pretty good deal. Good salary, good hours, good-working conditions. But the NFL is everybody's dream and few make it here (Fraser, 1998)

It must be noticed that a SFAB construction does not say anything about what is before but: what is blocked may be $p$ in $p$ but $q$, as in (22) where it is the certification which is blocked, or a move $p$ supports, as in (21) and Ducrot's description, or simply something else as in (25) where $p$ is the answer to an invitation that cannot be accepted because of SF $q$. The important point is that the status of $p$, and the relation of $p$ and $q$ are not at stake at all for unification to be a success, which allows for a great variety of such status and sometimes for the necessity to discuss the precise nature of the connective status of but.

\subsubsection{The SFBB construction}

The SFBB construction is a construction in which p occurs in a connective position and in which the Stopping Factor occurs before But. In most cases, it is associated with an unsuccessful stopping factor. Typical examples of SFBB constructions are example (20) and the following:

28) "This ugly cycle must end, it will leave scars that are not simple but it is within our power together to overcome them." (SF: scars that are not simple)

29) Nous n'avons le droit de rien dire sur les sondages à la sortie des urnes, dit une jeune hôtesse blonde qui peine à tenir sa langue, mais je peux vous dire que nous allons avoir une très belle fête. ("We are not allowed to say anything about the voting-day polls" says a young blond woman who has a hard time shutting up "but I can tell you we shall have a great celebration")

30) Israeli Prime Minister Ehud Barak said Tuesday it was too soon to tell if the violence in the West Bank and Gaza Strip was coming to an end, but he said if it was, Israel would act accordingly. (where SF = too soon).

31) It has been tough but we did it!! 


\subsubsection{The NI construction}

The NI construction is a variant of a SFBB $p$ but $q$ construction whose reading is the following: $p$ did not impede $q$. It concerns examples in which $\mathrm{p}$ should/could impede $\mathrm{q}$ and does not. Typical examples of SFBB constructions are example (19) and the following:

32) Defense Secretary William Cohen said he knew of no other specific threats against American forces in the region, but said he ordered an increased alert level for all U.S. forces around the world, including those in the United States. He is republican but honest.

33) She is ten years old, but brilliant already

34) He is republican but honest.

35) The top hole was for Bush, who was listed at top left; the second hole was for Buchanan, listed at top right, and the third hole was for Gore, listed under Bush on the left. Arrows linked the names with the proper hole, but some voters feared they had missed the arrows and punched the wrong hole.

36) It is yellow but I like it.

If we consider example (35), for instance, both readings i) that "Arrows linked the names with the proper hole" should prevent (stop) voters from choosing the wrong hole, so that this $p$ may unify with something in the indications encoded by but; and ii) that this may not have stopped them, so that the SF was no SF, are clear. Hence, there is both a SF before but, and a claim immediately after but that this SF was actually no $\mathrm{SF}^{6}$.

\subsubsection{The BT and NBT constructions}

The BT (Beyond that) and NBT (Not Beyond that) constructions are $p$ but $q$ connective constructions for which the question is not to know

\footnotetext{
${ }^{6}$ Concerning example (31) it must be borne in mind that the fact that republicans are dishonest is only an inferential consequence of the NI construction: what the NI interpretation of (31) implies is that "the fact of being republican does not impede him from being honest". There are however other SFBB interpretations of (31) which do not entail that republicans are dishonest, such as a situation in which the mere fact of being republican would be a stopping factor for something (hiring him) while the fact of being honest would be a decisive criterion overcoming this initial reluctance.
} 
whether a first movement was stopped or not but to know how far something is going. Consequently, they deal with gradable processes or moves, and the question is to know up to where or when the move may go on. NBT constructions are the most frequent, asserting that things did not go further than $p$. Typical examples of BT constructions are examples (15), (16), (19) and the following:

37) In Delaware, state House majority leader Wayne A. Smith, a Republican, said Bush holds "higher ground and more legitimacy" than Gore because the Florida tally so far gives the state to Bush. But, Wayne added, "neither of them deserve to be placed on a pedestal in this matter."

38) Israel has said it would consider less than full control, but would not accept Palestinian rule over the compound, former home of the biblical Jewish Temple, the most sacred shrine of Judaism.

39) Secretary of State Madeleine Albright has spoken of "accountability" and respect for "the rule of law" but not of a Milosevic extradition.

40) The Royal Swedish Academy of Sciences, which also chooses the chemistry and economics winners, invited nominations from previous recipients and experts in the fields before whittling down its choices, but deliberations are conducted in strict privacy.

41) Il faisait frais, le ciel était gris, quelques gouttes de pluie mais pas d'averse.(The weather was fresh, the sky was grey, a few drops but no showers.)

42) The crippled warship USS Cole was listing but still afloat in a Yemeni port as investigators tried to find who planned its apparent bombing.

Typical examples of BT constructions are the following:

43) "I cannot see that Hezbollah was to be content with its May victory, but it will take the fight into Israel proper," (where BT is being satisfied, and hence not going further, with fighting Israel out of Lebanon)

44) Devant le refus de la France, de la Chine, mais surtout de la Russie, qui menaçait d'opposer son véto, Washington et Londres y ont renoncé. (Confronted with the refusal of France, China but above all Russia, who threatened to oppose a veto, Washington and London withdrew their proposition)

45) Harry plays tennis but he (also) plays golf (Fraser, 1998). 
The frequent uses of mais (and but) in non seulement... mais encore (not only ...but (also)) constructions are closely related to BT constructions:

46) But for the most part, in more than 100 interviews conducted by Associated Press reporters across the country, citizens seemed exhilarated not only by the excitement of this particular race, but by the chance to watch and discuss American history as it unfolded with each passing moment.

\subsubsection{The NY construction}

The NY (Not Yet) construction is a $p$ but $q$ connective construction, which shares with NBT the fact that $p$ and $q$ are often different steps of a co-oriented process, but it adds the idea that something has not been completed yet; in other words, something has been engaged but not accomplished:

47) Bush spokesman Andrew Malcolm said the campaign was studying the close New Mexico result but would not make a decision soon about requesting a recount.

48) Au micro, un animateur annonce "l'arrivée du président Bush" pour dans 20 minutes. Mais 20 minutes après, il n'est toujours pas là. (A voice announces the "arrival of president Bush" in twenty minutes. But twenty minutes later, he is still not there").

\subsubsection{FMWM constructions}

The FMWM (First Move Wrong Move) construction is a $p$ but $q$ connective construction, in which $p$ and $q$ are different alternatives (or in which q shows that a first move is problematic and should be abandoned), the first move (idea, explanation, hypothesis, plan) being abandoned because of $q$ or something included in $q$. This kind of use is different from the one we have seen so far because we are in contexts in which we have no go and stop or stop and go, as in SFAB or SFBB, or discrete levels of completeness, as in NBT, but rather alternatives, i.e. moves for which each move means the end of its alternative. Graphically, we have something like: 


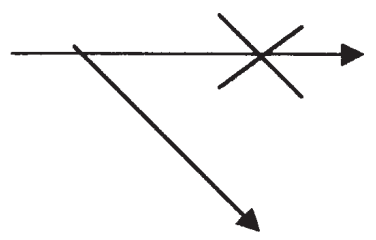

49) this curious flight pattern has commonly been thought to be a communal defense system: $[\ldots \ldots \ldots . . .$.$] . But Eshel suggested a different explanation.$

50) I don't' know. It's a very - a lot of people do think so. That at one time it's just gonna be one. But I really don't know.

51) That idea has certain plausibility. But years of observation raised so many puzzling questions that we finally dared ask ourselves whether the calls were indeed meant as warnings.

52) One could possibly understand the first bark as a warning to the group, and perhaps the second and the third as efforts to make all members of the group aware of the danger. But what is the point of repeating the calls after the entire group has already taken cover?

53) He is not fifteen but sixteen.

Another illustration of a little more complex FMWM interpretation would be:

54) Then you must turn to the left but at the second traffic lights.

If we compare (54) with and without but, we can graphically express what the use of but adds to the sentence, showing what the speaker wants to change in the initial plan of his/her addressee:

ti $\mathrm{ti}+1$
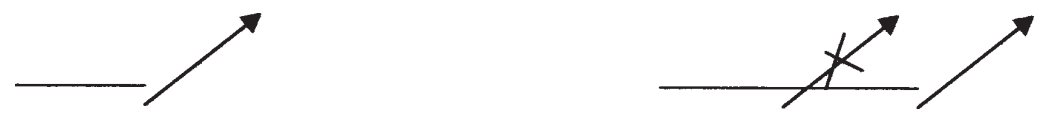
it is with such examples that the something must be stopped indication and the way it unifies contextually may be shown to be more effective than a strictly aspectual description of but.

\subsubsection{Some NSFBB constructions}

Given the little space available here, I shall turn now to a few examples that illustrate the fact that even though there are some interpretative patterns which account for a statistically significant part of the uses of but, it is also the case that interpretation is not forcefully guided by such interpretative patterns and that unification can be purely local. If it is indeed difficult to estimate what years of experience in interpreting uses of but may lead to in terms of memorization of semantic constructions, it is clear nevertheless that a great number of uses unify contextually very well without fitting precisely into prior models: interpretation is by definition an open process, the only real constraint being contextual unification. Examples like (55), (56) or (57):

55) "I have no reason to think this was anything but a senseless act of terrorism," said Adm. Vern Clark, the chief of naval operations

56) - Je vais m'en aller. - I am going to leave

- Mais personne ne te retient. - But nobody is stopping you. (Ducrot et al, 80).

57) The Americans have managed to elect a dead man but not a president.

clearly show that unification is an open process and that constructions may interfere. Indeed, (55) does state that there is no SF or S/alternative that could prevent the speaker from speaking of senseless terrorism while but itself receives the nothing else interpretation it would have in This is but a senseless act of terrorism. As for (56), unification goes even one step further: the but answer implies that saying "I am going to leave" was a way of fishing for an answer such as "please don't!", which would have stopped him from leaving, and this answer asserts that nothing like that will come. The "please don't!" SF hence has remained virtual all along the exchange. The whole interpretation thus depends on the pragmatic possibilities of saying something in order to force people to prevent you from doing something. This is a good way of understanding what instructions, 
indications, indexicality and contextual unification are all about: if morphemes are telling us very precisely what has to be looked for, they say nothing about what we will find when looking nor much about where to look. Now having dealt with only a small portion of the connective uses of but, let's move next to the non-connective ones.

\subsection{Non-connective uses}

If, as I have shown, it is possible to account for a large diversity of connective uses of but, without any reference to the notions of contrast, expectations or to the idea of a basic functional meaning that would tell us something about the relationship between the utterances connected, this doesn't mean that as a lexeme and as a connective but does not receive a connecting interpretation: any semantic unit, when inserted in a construction, receives a constructional interpretation. Actually, I have elsewhere (see Nemo, 1999a, for a recent formulation) described this (actually scalar) interpretation. I do not mean to say that what Ducrot has carefully described does not exist, that there are no such things as argumentative orientations for instance, or that they are not important to understand but or mais. What I mean is that this last 'meaning' is clearly constructional, not morphemic, and that it is compositional (and possibly memorized) and not encoded. To prove it, I need to show now that the indicational description introduced earlier allows us to understand all the non-connective uses of but, so that it indeed describes the morpheme but and not only the DM but.

\subsubsection{The But for construction}

Translated into French as sans (without), but occurring in but for constructions is very easy to account for with the indication proposed earlier. Since in But for $X, Y$ constructions, $\mathrm{X}$ is the factor that has blocked (or impeded) a process whose result was Y. A typical example would be:

10) But for Peter, I would be dead.

What (10) means, indeed, is that there was a process that would have resulted in my death if it had not been interrupted before completion by 
something, and here specifically by someone: Peter. Little more need to be added here but other illustrations of this interpretative pattern are:

58) But for his tenacity, he would never have succeeded.

59) Some of the government supporters will say things might have been worse but for the free trade agreement.

60) I am sure but for his larger duties he wished he could have been there on the convention floor in the heat and excitement of that occasion.

In (58), it must be remarked, there is a matter of degree, as the free trade agreement did not prevent things from getting bad, but did stop them from getting worse.

\subsubsection{The quantificational constructions}

Translated into French as sauf or excepté (except), this use of but is quantificational: completeness hence is not aspectual but quantitative. With All but $X Y$ or everyone but $X Y$ etc., $\mathrm{X}$ is what forbids one to say that $\mathrm{Y}$ is the case. An overwhelming tendency does not go to its end.
$0 \%$
$100 \%$
$0 \%$
X Y

Typical cases are examples (9) and (12) and the following:
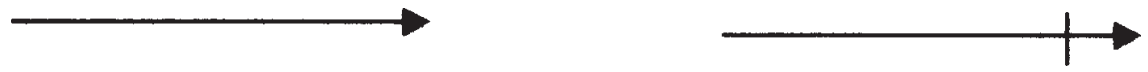

61) The response from all but the most vociferous critics was that yes, probably any bill was better than no bill.

\subsubsection{The NOO construction}

Translated into French as que or seulement (only), this use of but is interesting because i) it shows that the "something is blocked" indication encoded by but may unify not with what is the case, but with alternatives to something: there are indeed No Other Options than something, and hence what is blocked are these options; ii) its only interpretation shows 
that only may refer to a quantitative or qualitative limitation (both readings being accessible with all but). Typical examples are examples (5) to (8).

\subsubsection{The but $\mathrm{n}$ (only) construction}

Another interpretation of but may remind us of the NBT construction, namely the only interpretation. Associated with numbers, as in (4) or:

62) Of these processes, regular sound change is but one, even in phonology.

63) These are but a few in-between claims in the article.

it receives a "not more than n" interpretation, itself with various pragmatic interpretations (minimizing or not). Specifically, it is often used in a postGricean argumentative way to say that not everything has been said, that more could be said but will not, so that it is this time what is said which is incomplete or completable.

\subsubsection{The almost construction}

Non-connective uses of but contribute to the propositional content of the utterance in which they are included: saying This bird species has disappeared and saying This bird species has but disappeared clearly communicates a different propositional content, for it has different truth conditions. Specifically, the rather direct relationship between the idea that something has not gone to its end and the meaning of almost, makes it easy to understand how in but $\mathrm{P}$ (in which $\mathrm{P}=$ predicate) constructions, but may indicate that $\mathrm{P}$ is not completely the case. Typical illustrations include examples (1) to (4) and the followings:

64) On Monday, key Kostunica aide Zoran Djindjic indicated Yugoslavia's new management was out to rebuild ties to the West which were all but destroyed under Milosevic.

65) These results are all but absolute. In twenty years, only four observations of the opposite are recorded. 


\subsection{Non-connective uses}

$B u t$, as we have just seen, may be used as a preposition and/or an adverb, etc. Its constructional meaning, however, is similar: it indicates that the predicates, quantificators or quantity it associates with are either not fully completed (or true) or represent only a part of a larger set (ex: These are but a few in-between claims in the article) that could be spelled out completely but are not. Hence, the indication that "something is stopped" before completion is direct in such uses. These uses then cannot be considered as independent from the connective ones, which proves the existence of a single morpheme, whose indexical meaning is completely independent of the syntactical positions it may occupy. The idea that the linguistic meaning of but could be predicted from its syntactical status of discourse marker, and categorical status of contrastive discourse marker, and thus that it must consist in establishing a specific kind of relationship between two connected segments, is here directly falsified: the possibility for a morpheme to become a discourse connective depends on its linguistic meaning, which does not explain what is done but only how it is done, and which must explain why so many things can be done by the same morpheme. But, exactly as toujours or encore (Nemo, 1998a; 1999a), does not encode a procedural meaning in some of its uses and a conceptual meaning in the others; it encodes the same indicational-indexical information in all of them.

\section{Conclusion}

Given space constraints, I had to limit myself almost entirely to a presentation of English but, and even only to some of its most common non-dialogical uses. Similarly, the discussion of these results will be limited. Five points nevertheless may be highlighted:

- this description is the first available of the morpheme but, since it is a description of all the uses of but, whether connective or not;

- it shows that but does not encode functional or metacommunicational information, but that it may receive a such functional or metacommunicational interpretation when it is used; 
- it shows that but's contribution to propositional content in nonconnective uses is also a matter of interpretation of the indications so that neither the so-called pragmatic meaning of but in connective uses nor the so called semantic truth-conditional meaning of but in non-connective uses are actually encoded meanings: what morphemes encode is indexical information that may refer to language itself or give access to aspects of the non-linguistic reality without any inflection;

- it shows that the ubiquity of but is linked to a very concrete meaning (something is stopped) combined with the absence of constraints on the nature of the elements involved;

- it shows that the indexical nature of language use (Find in the context what is stopped) allows to understand how a fixed (encoded) meaning may coincide with a great variety of interpretations, memorized insomuch as contexts are repetitive, so that both the semanticist's claim that there is a fixed a semantic meaning and the pragmaticist's claim that there is no such meaning outside of language uses do describe an aspect of the reality, but fail when they believe either that this fixed meaning would be accessible through direct intuition or dependent on the nature of the language game which is played (such as contrasting or reformulating).

Two general conclusions follow:

1) what these results clearly show is that lexeme (i.e. word) based semantics cannot be efficient when it comes to describe linguistic (encoded) meaning, and that the reason for this is that the lexematic level is not the basic semantic level but an intermediate one, the level of memorization of constructional interpretations (or of purely local and contextual interpretations). This of course has strong implications for our understanding of semantics, the most important one being that we cannot talk of encoded lexematic meaning, since (encoded) linguistic meaning is morphemic and cannot be studied without studying all the uses of a morpheme, and since lexical meaning is a matter or memorization of contextual interpretations. As we have seen, but, as table, may thus be described as a single semantic unit with various (more or less) lexicalized meanings (i.e. memorized interpretations) and with a great diversity of less stable and sometimes unique interpretations. 
2) as far as describing discourse connectives is concerned, the conclusion is somehow similar: from a strictly pragmatic perspective, it may be legitimate to approach discourse words in terms of functional families (reformulative discourse connectives, contrastive discourse markers, deductive ....) but as far as semantics is concerned, focusing on the possibility to replace discourse connectives one with another means focusing on constructions and does not allow us to make any hypothesis about linguistic meaning. Instead, we must understand that the main difficulty in semantics is to separate morphemic meaning from constructional meaning, both being, as long as they are clearly separated, legitimate objects of a linguistic theory of meaning. Given the fact that polyfunctionality is an empirical reality which cannot be ignored, we should hence adopt a morphemic approach rather than use our intuition to clarify a specific interpretation (or context of interpretation) as central and consider other uses as deviation or results of a fading of this central meaning.

In both cases, because the description I have presented today is a (short) illustration of the IIS approach, it also shows that it may be time for semantics to consider that thirty years of careful study of linguistic signs, starting with discourse words, may have given us enough experience to start understanding how language works.

10 rue de Tours. 450720 Orléans Cedex 02 Francois.Nemo@univ-orleans.fr

\section{REFERENCES}

Anscombre, J. C. \& O. Ducrot. 1977. Deux mais en Francais? Lingua 43: $23-40$.

1986. Argumentativité et informativité. In? M. Meyer (éd.) De la métaphysique à la rhétorique. Bruxelles: Éditions de l'Université de Bruxelles? 79-94.

Anscombre, J.-C \& O.Ducrot. 1983. L'argumentation dans la langue. Bruxelles: Mardaga.

Blakemore, D. 1992. Understanding Utterances: An Introduction to Pragmatics (Blackwell Textbooks in Linguistics). Blackwell Publishers. 
Cadiot, A. E alii .1979. "Oui mais non mais" ou: Il y a dialogue et dialogue. Langue française. 42: 94-102.

CADIOT, P. 1993. Représentations d'objets et sémantique lexicale: qu'est ce qu'une boîte?. Journal of French Language Studies, vol. 4. Cambridge University Press: 1-23.

Ducrot, O. 1972. Dire et ne pas Dire. Zème édition 1991, Paris: Hermann. Ducrot, O. et alii (1980a), Les mots du discours, Paris: Les Éditions de Minuit.

Ducrot, O. 1980b. Analyses pragmatiques. Communications 32 (Les actes de discours): 11-60.

1983. Opérateurs argumentatifs et visée argumentative. Cahiers de Linguistique française, 5: 7-36.

1987. L'interprétation en sémantique: un point de départ imaginaire. In: O. Ducrot (1972, [1991]): 307-323.

FIsCHER, K. 2000. Discourse particles, turn-taking and the Semantics/ Pragmatics Interface. Revue de Sémantique et Pragmatique, 8: 81-99s.

Fischer, K. \& F. Nemo. 2000. Aber, Mais, But: Integrating Semantics,

Grammar and Pragmatics. Working paper presented at SIC-CSP2000.

Fraser, B. 1996. Pragmatic markers. Pragmatics. Vol 6. N²: 167-190.

1998. Contrastive Discourse Markers in English. In: Andreas H. Jucker and Yael Ziv. Discourse Markers: Descriptions and Theory. Pragmatics \& Beyond, 57. Amsterdam: John Benjamins Pub Co.

Luscher, J-M. 1994. Connecteurs: des guides pour l'interprétation. In: Moeschler and al. 1994: 175-227.

Moeschler, J. et al. 1994. Langage et pertinence. Nancy: Presses Universitaires de Nancy.

Nemo, F. 1998a. Enfin, encore, toujours entre indexicalité et emplois. Actes du XXII ${ }^{e}$ Congrès International de Linguistique et de Philologie Romanes. Bruxelles. Tome VII: Sens et fonctions, XIV. Tübingen: Max Niemeyer Verlag.

1998b. Discourse Connectives: Polyfunctionality, Meaning and the Semantic/Pragmatic Interface. Working paper presented at the Sixth International Pragmatics Conference (Ipra, Reims).

1999a. The Pragmatics of Signs, The Semantics of Relevance, and The Semantic/Pragmatic Interface. In: Ken Turner (ed.) The Semantics-Pragmatics Interface from Different Points of View. CRiSPI Series, Volume 1. Amsterdam: Elsevier Science: 343-417. 
1999b. Mots de discours: étude de mots, étude du discours? Working paper presented at the 2th Rencontres de Sémantique et Pragmatique (Orléans). 2001. Sémantique des pertinences énonciatives. Berne: Peter Lang. 2001 Pour une approche indexicale (et non procédurale) des instructions sémantiques. Revue de Sémantique et Pragmatique, volume 9-10.

Rossari, C. 1994. Les opérations de reformulation. Berne: Peter Lang.

Schiffrin, D. 1987. Discourse markers. Cambridge: Cambridge University Press.

Sperber, D. \& D. Wilson, D. 1986. Relevance. Oxford: Basil Blackwell. Wilson, D. \& D. Sperber. 1990. Forme linguistique et pertinence. Cabiers de linguistique francaise, 11: 13-35. 